\title{
Availability of Adequately Iodized Salt at Household Level and Associated Factors in Dire Dawa, Eastern Ethiopia
}

\author{
Anteneh Berhane ${ }^{1}$, Negga Baraki ${ }^{2}$, Berhanu Seyoum Endale ${ }^{3}$ \\ ${ }^{1}$ School of Medicine, College of Medicine and Health Sciences. Dire Dawa Universitv. Ethiopia \\ ${ }^{2}$ Department of Environmental Health Sciences, College of Health and Medical Sciences, Haramay a University, Ethiopia \\ ${ }^{3}$ Department of Medical Laboratory Sciences, College of Health and Medical Sciences, Haramaya University, Ethiopia
}

\begin{tabular}{l}
\hline \hline Article Info \\
\hline Article history: \\
Received May 17, 2016 \\
Revised Aug 20, 2016 \\
Accepted Aug 26, 2016 \\
\hline
\end{tabular}

Keyword:

Ethiopia

Dire Dawa

Household

Iodized salt

Urban people

\begin{abstract}
In Ethiopia, Iodine Deficiency Disorder has been recognized as a serious public health problem for the past six decades. In 2011, an estimated 12 million school-age children were living with inadequate iodine, and 66 million people were at risk of iodine deficiency. One out of every 1000 people is a cretin mentally handicapped, due to a congenital thyroid deficiency, and about 50000 prenatal deaths are occurring annually due to iodine deficiency disorders. Only 5.7\% of the households were using iodized salt in Dire Dawa city Administration, which is below the legal requirement.This study assessed availability of adequately iodized salt at household level and associated factors in Dire Dawa town, East Ethiopia. Community based cross-sectional study was carried out among households in Dire Dawa town during March 16-26, 2015. Multistage sampling technique was used. Data were collected using a pretested and structured questionnaire by a face-to-face interview technique. Bivariate and multivariate analyses were performed to check associations and control confounding. A total of 694 participants were participated. The availability of adequately iodized salt $(\geq 15$ parts per million) in the study area was $7.5 \%(95 \% \mathrm{CI}$; 5.6-9.5). Multivariate result showed that health information about iodized salt $(\mathrm{AOR}=8.96,95 \% \mathrm{CI} ; 4.68-17.16)(\mathrm{p}=0.03)$, good knowledge about iodized salt $(\mathrm{AOR}=9.23,95 \% \mathrm{CI} ; 3.34-25.5)(\mathrm{p}=0.01)$ and using packed salt $(\mathrm{AOR}=3.99,95 \% \quad \mathrm{CI} ; 1.48-10.73) \quad(\mathrm{p}=0.006)$ were associated with availability of adequately iodized salt at household level. Availability of adequately iodized salt at household level was very low. Hence, households should be sensitized about importance of iodized salt and its proper handling at the household level.
\end{abstract}

Copyright $(0) 2016$ Institute of Advanced Engineering and Science. All rights reserved.

\section{Corresponding Author:}

Anteneh Berhane,

School of Medicine,

College of Health and Medical Science,

Dire Dawa University, Ethiopia.

Email: addiskidan21@gmail.com

\section{INTRODUCTION}

Healthy humans require iodine, an essential component of the thyroid hormones, thyroxin, and triiodothyronine. Failure to have adequate iodine leads to insufficient production of these hormones, which affect many different parts of the body, particularly muscle, heart, liver, kidney, thyroid gland, and the development of brain. Inadequate hormone production adversely affects these tissues resulting in the disease status known collectively as Iodine Deficiency Disorders (IDD). These include mental retardation, defects in development of the nervous system; goiter, physical sluggishness, growth 
retardation, reproductive failure, increased childhood mortality, and economic stagnation.the most devastating of these consequences are on the development of human brain [1].

Globally, an estimated 66 million people were at risk of iodine deficiency (ID) and 12 million school-age children were living with inadequate iodine level [3]. Despite the improvements in iodine status between 2007 and 2013, a significant burden of ID still remains in Africa. According to 2013 report, 11 Africa countries were iodine deficient, 6 countries were moderately iodine deficient and 5 countries had mild ID. The largest burden of ID in 2013 was because of large populations, remains in Ethiopia, Algeria, Sudan, Morocco, Angola, Ghana and Mozambique [2]. Ethiopia had the lowest coverage of adequately iodized salt amongst countries in Sub-Saharan Africa during this period [3]. In 2012, a study conducted in Ethiopia, showed that IDD is a serious public health problem for the past six decades.

Universal salt iodization has been extremely effective at reducing the burden of IDD and represents a major global public health success (Seal, A.J.et al, 2006). A national iodization strategy was developed by the Ethiopian government and passed new salt legislation since March 2011 which requiring salt for human consumption should be iodized [4]. The actual availability of iodine from iodized salt at the consumer level can vary widely due to a number of factors such as monthly income; heard information, knowledge, and type of salt used and place of purchasing salt. According to the 2011 Ethiopian Demographic and Health Survey (EDHS) repot, only 15.4 percent of the households were using iodized salt [5-6]. Therefore, this study was conducted to assess the availability of adequate iodized salt at household's level and associated factors in Dire Dawa City, Eastern Ethiopia.

\section{METHODS}

Cross-sectional study design was carried out during March 16-26, 2015, in Dire Dawa City Administration which is located in Eastern Ethiopia Dire Dawa is $515 \mathrm{~km}$ East of Addis Ababa. The city is divided into 9 urban kebeles. According to the 2007 Ethiopian census report, Dire Dawa has a total population of 369,541 [7]. The study population consists of people residing in selected urban kebele areas of Dire Dawa city administration and selected using multistage sampling technique. The sample size was determined by using both single double population proportion formulas. The following assumptions were made: $28.9 \%$ proportion of iodinated salt [8] 95\% confidence levels, $5 \%$ margin of error, and design effect of 2. Then, $10 \%$ non-response rate was considered, making the final sample size 694.

First, 4 kebeles were selected using simple random sampling technique. Then, sample was allocated proportional to the household size of each kebele. Then random table method until the sample size of the household is reached from each selected kebele. The member of the household who is responsible for purchasing food items and mostly involved in food preparation in the selected households was interviewed.

Socio-demographic characteristics, income, educational status, knowledge, environmental factors were collected using pre tested structured questionnaire by a face-to-face interviewing technique. To assess the use of iodized salt at the household level, interviewers asked households to provide a teaspoon of salt used for cooking. The availability of iodine in the salt was analyzed using a portable digital electronic iodine checker. Data were collected by 15 trained female diploma nurses. Two B.Sc. Environmental health officers were also recruited as supervisors.

After data collection, each questionnaire was checked for completeness and consistency by after data collection, each questionnaire was checked for completeness and consistency by supervisors. The data were entered into Epi Info version 3.5 and transferred to SPSS version 16 for analysis. Association between dependent and independent variables was assessed by using a logistic regression model. Variables with a $\mathrm{p}$ value $\leq 0.25$ in the bivariate analysis were entered into multiple logistic regression models to control for confounding variables. Odds ratio with $95 \%$ confidence interval was calculated to show the as sociations between independent variables and outcome variable. $P$ value $\leq 0.05$ was considered statistically significant. Adequately iodized salt at household level was defined as salt sample which has $\geq 15$ parts per million (PPM) of iodine. Participants who scored above the mean for knowledge questions were considered as having good knowledge about iodized salt.

Ethical clearance was obtaining from Institutional Health Research Ethics Review Committee of the Collage of Health and Medical Sciences, Haramaya University. A formal letter of cooperation was writing for Dire Dawa Health Bureau and Ethiopia Food, Medicine \& Health Care Administration and Control Authority Eastern Branch. Informed consent was obtained from each of the member of the household who was responsible for purchasing food items and mostly involved in food preparation before conducting of the interview was conducted. An interview was carrying out privately in a separate room. Names or personal identifiers were not included in the questionnaires in order to ensure participants' confidentiality. 


\section{RESULTS AND ANALYSIS}

\subsection{Socio-Demographic Characteristics of the Study Participants}

A total of 694 study participants were involved in the study with a response rate of $100 \%$. The Mean age of the participants was 30.64 years with $( \pm$ SD 8.749$)$ years ranging from $16-60$ Year. The predominant sex of the total (694) study participants were females, accounting for 545 (78.5\%), and208 (30\%) had at least secondary school level in education (9-12). Out of the 694 participants, 446 (64.3\%) were married, $185(26.7 \%)$ were Amhara by ethnicity, 278 (40.1\%) were Orthodox Christians, and 164 (23.6\%) were private sector employees by occupation. Six hundred and twenty one $(89.5 \%)$ of the study households had family size of $\leq 5$, and the average monthly income of the families was $\geq 2000$ Ethiopian Birr (ETB) in $414(59.7 \%)$ of the households (Table 1).

Table 1. Socio-Demographic Characteristics of Study Participants at Dire Dawa, Eastern Ethiopia,

\begin{tabular}{|c|c|c|c|}
\hline \multicolumn{4}{|c|}{$2015(n=694)$} \\
\hline Variables & Label & Frequency & Percent (\%) \\
\hline \multirow[t]{2}{*}{ Sex } & Male & 149 & 21.5 \\
\hline & Female & 545 & 78.5 \\
\hline \multirow[t]{3}{*}{ Age Group In years } & $16-29$ & 350 & 50.4 \\
\hline & $30-44$ & 284 & 40.9 \\
\hline & $\geq 45$ & 60 & 8.6 \\
\hline \multirow[t]{4}{*}{ Educational status } & Illiterate & 94 & 13.5 \\
\hline & Primary school(1-8th) & 88 & 12.7 \\
\hline & Secondary school(9th-12th) & 208 & 30.0 \\
\hline & Tertiary school & 178 & 25.6 \\
\hline \multirow[t]{4}{*}{ Current Marital status } & Single & 187 & 26.9 \\
\hline & Married & 446 & 64.3 \\
\hline & Widowed & 40 & 5.8 \\
\hline & Divorce & 21 & 3.0 \\
\hline \multirow[t]{5}{*}{ Religion } & Orthodox & 278 & 40.1 \\
\hline & Muslim & 245 & 35.3 \\
\hline & Protestant & 114 & 16.4 \\
\hline & Catholic & 50 & 7.2 \\
\hline & Others & 7 & 1.0 \\
\hline \multirow[t]{6}{*}{ Ethnicity } & Amhara & 185 & 26.7 \\
\hline & Oromo & 162 & 23.3 \\
\hline & Gurage & 88 & 12.7 \\
\hline & Somali & 112 & 16.1 \\
\hline & Tigrai & 54 & 7.8 \\
\hline & Others & 93 & 13.4 \\
\hline \multirow[t]{6}{*}{ Occupation } & Governmental employee & 130 & 18.7 \\
\hline & Private sector employee & 164 & 23.6 \\
\hline & Daily laborer & 43 & 6.2 \\
\hline & House wife & 152 & 21.9 \\
\hline & Merchant & 147 & 21.2 \\
\hline & Others & 58 & 8.4 \\
\hline \multirow[t]{2}{*}{ Family size } & $\leq 5$ & 621 & 89.5 \\
\hline & $>5$ & 73 & 10.5 \\
\hline \multirow[t]{4}{*}{ Average Family Income(Birr) } & $<1000$ & 110 & 15.9 \\
\hline & $1000-1499$ & 123 & 17.7 \\
\hline & $1500-1999$ & 47 & 6.8 \\
\hline & $\geq 2000$ & 414 & 59.7 \\
\hline
\end{tabular}

\subsection{A vailability of Adequately Iodized Salt at the Household Level}

From the total of 694 sampled households, adequate amount of iodized s alt was found only in $52(7.5 \%)(95 \%$ CI; $5.6-9.5)$ of the 694 sample households i.e. $>15$ ppm (Figure 1). Five hundred and twenty six $(75.6 \%)$ of the respondent were purchased salt from retail shop. Out of these, $39(5.6 \%)$ of samples had adequate amount of iodine in salt. $600(86.5 \%)$ of the respondents were using common salt (coarse salt without packet) and out of which $0(0 \%)$ of samples are have not adequate amount of iodine in salt (0-14.9 ppm) and also of which 94 samples of packed salt 42 samples are have not adequate amount of iodine in salt. 


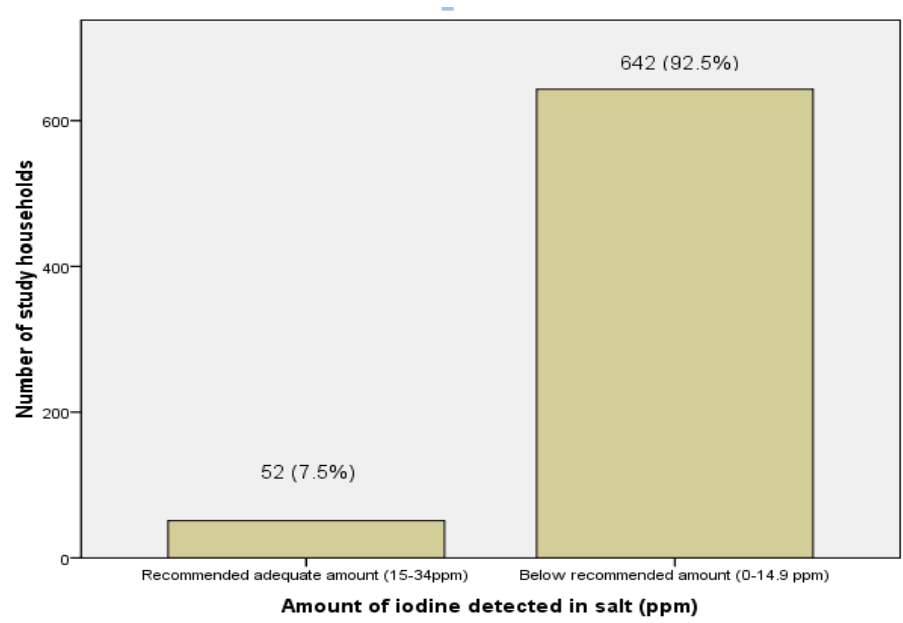

Figure 1 Amount of Iodine Detected in Household Salt, Eastern Ethiopia, 2015

\subsection{Factors Associated with Availability of Iodized Salt at Household Level \\ 3.3.1. Knowledge and Health Information of the Respondents about Iodized Salt and Iodine Deficiency Disorders (IDD).}

Five hundred forty eight $(78.9 \%)$ heard about iodized salt from different sources of information. Out of 548, $469(67.6 \%)$ got the information from radio/television.677 (97.6\%) participants responded that they did not receive any information regarding importance of iodized salt and IDD from health workers or health extension workers. Moreover, 677 (97.6\%) responded that health care workers did not teach or inform them about factors that lead to loss of iodine during salt utilization ( Table 2).

Table 2. Knowledge and Health Information of Study Participants about Iodized Salt in Dire Dawa,

Eastern Ethiopia, 2015

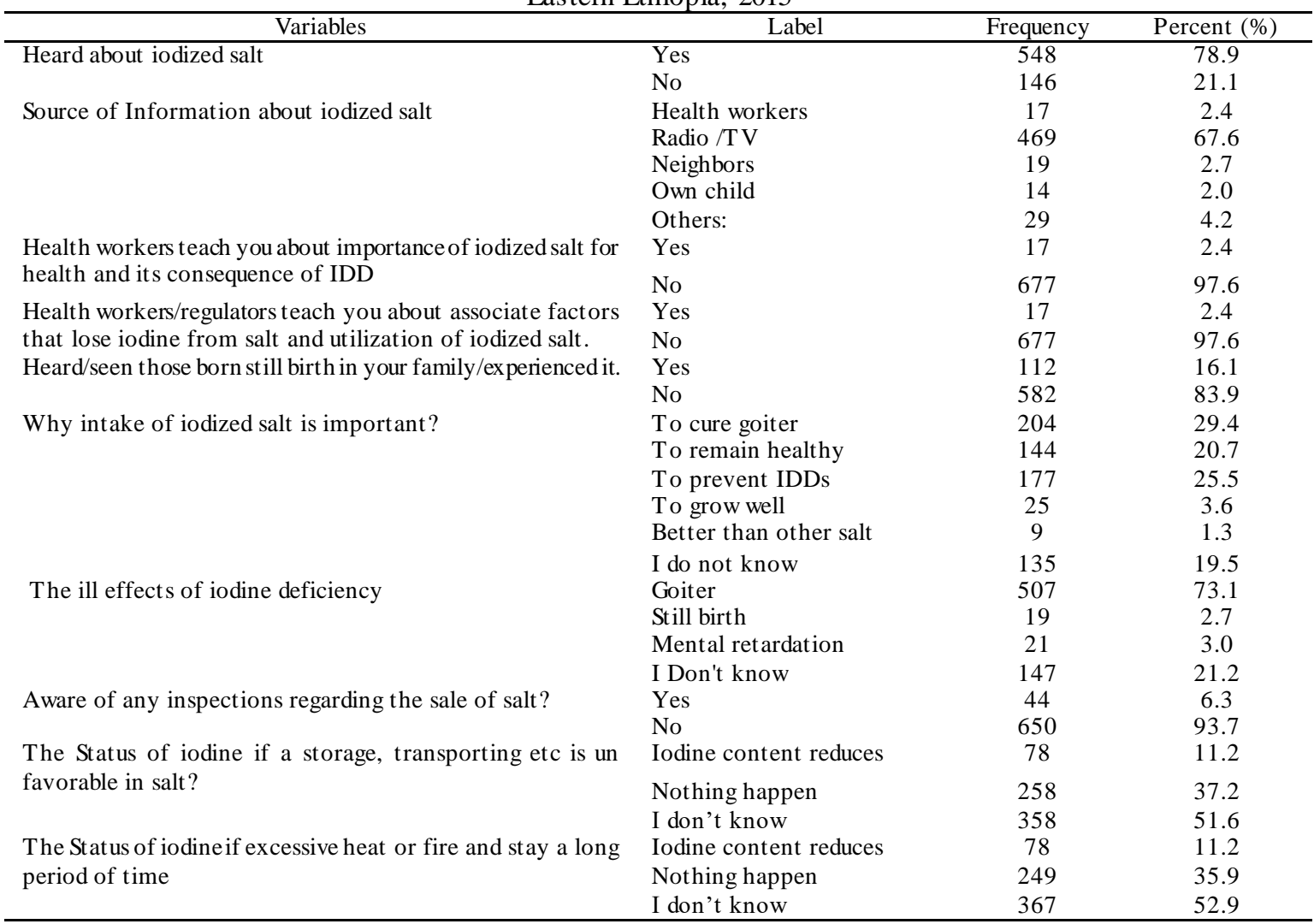


Regarding knowledge of participants about the importance of intake of iodized salt, 204 (29.4\%) responded that it cures goiter and, 507 (73.1\%) reported that iodized salt is important to prevent goiter. 147 (21.2\%) did not know the ill effects of ID and 650 (93.7\%) were not aware of any inspections regarding the sale of salt. Only $145(20.9 \%)$ had knowledge on what may happen to the iodine concentration in iodized salt during its transportation, storage, distributing and at retail shops, (i.e. Before it reaches the consumers). 155 (22.3\%) had good knowledge on the status of iodine if iodized salt is not stored properly before it reaches to the consumer, (i.e. exposed to excessive heat, direct sun light, moisture and long storage times) (Table 2).

\subsubsection{Practice of Respondents Regarding the Use of Iodized Salt of the Households}

Six hundred and forty (92.2\%) respondents said they store the salt in a dry place. Twenty two (3.2\%) of them wash salt to remove its impurities. 689 (99.3\%) of respondents stored the salt for less than two months after purchase and $629(90.6 \%)$ of participants reported their salt containers had cover. Five hundred and twenty six $(75.6 \%)$ of the respondent said they purchase salt from retail shop and 600 (65.9\%) of the respondents were using non-packed (Table 3).

Monthly income, heard information, knowledge, type of salt used and place of purchasing salt were factors associated with the amount of adequately iodized salt (outcome variable) in the bivariate logistic regression analysis. In the multivariate logistic regression, only health information, knowledge, place of purchasing salt and type of salt used were as sociated with the outcome variable.

Table 3. Practice of Study Participants about Iodized Salt in Dire Dawa, Eastern Ethiopia, 2015, (n=694)

\begin{tabular}{llcc}
\hline \multicolumn{1}{c}{ Variables } & \multicolumn{1}{c}{ Label } & Frequency & Percent $(\%)$ \\
\hline Place of salt storage & Dry place & 640 & 92.2 \\
& Moisture area & 9 & 1.3 \\
Washing salt & Others & 45 & 6.5 \\
& Yes & 22 & 3.2 \\
Duration of salt storage & No & 672 & 96.8 \\
& $\leq 2$ months & 689 & 99.3 \\
Use cover for salt container & $>2$ months & 5 & 0.7 \\
& Yes & 629 & 90.6 \\
Place of purchasing salt & No & 65 & 9.4 \\
& Open Market & 24 & 3.5 \\
Type of salt used & Retail shop & 647 & 93.2 \\
& Super market & 23 & 3.3 \\
& Non-packed & 505 & 72.8 \\
\hline
\end{tabular}

Table 4. Factors Associated with Availability of Adequately Iodized Salt at Household Level in Dire Dawa, Eastern Ethiopia, 2015.

\begin{tabular}{|c|c|c|c|c|c|}
\hline \multirow{2}{*}{ Variables } & \multicolumn{2}{|c|}{ Concentration of iodine } & \multirow{2}{*}{$\operatorname{COR}(95 \% \mathrm{CI})$} & \multirow{2}{*}{$\operatorname{AOR}(95 \% \mathrm{CI})$} & \multirow{2}{*}{ P-value } \\
\hline & $<15 \mathrm{ppm}$ & $>15 \mathrm{ppm}$ & & & \\
\hline \multicolumn{6}{|l|}{ Marital status } \\
\hline Single & 174 & 13 & 1 & & 0.5 \\
\hline Married & 417 & 29 & $0.93(0.47-1.83)$ & $0.91(0.41-2.02)$ & 0.82 \\
\hline Widowed & 33 & 7 & $2.83(1.05-7.65)$ & $1.93(0.56-6.59)$ & 0.292 \\
\hline Divorced & 18 & 3 & $2.23(0.58-8.57)$ & $1.97(0.32-12.07)$ & 0.46 \\
\hline \multicolumn{6}{|c|}{ Health information } \\
\hline Yes & 526 & 22 & 1 & 1 & 1 \\
\hline No & 116 & 30 & $0.06(0.009-0.48)$ & $8.96(4.68-17.16)$ & 0.03 \\
\hline \multicolumn{6}{|l|}{ Knowledge } \\
\hline Poor & 510 & 48 & $3.1(1.1-8.76)$ & $9.23(3.34-25.5)$ & 0.01 \\
\hline Good & 132 & 4 & 1 & 1 & 0.01 \\
\hline \multicolumn{6}{|l|}{ Purchasing place } \\
\hline Open Market & 21 & 3 & $0.09(0.02-0.4)$ & $0.026(0.004-0.197)$ & 0.01 \\
\hline Retail shop & 612 & 35 & $0.03(0.01-0.91)$ & $0.013(0.003-0.065)$ & 0.01 \\
\hline Super market & 9 & 14 & 1 & 1 & 1 \\
\hline \multicolumn{6}{|l|}{ Type of salt used } \\
\hline Non packed & 458 & 47 & $3.77(1.47-9.64)$ & $3.99(1.48-10.73)$ & 0.006 \\
\hline Packed & 184 & 5 & 1 & 1 & 1 \\
\hline
\end{tabular}

P-value is significant at $\alpha<0.05$; COR=Crude Odds Ratio; AOR=Adjusted Odd Ratio; CI=Confidence Interval. 
Study participants who had health information about iodized salt were 9 times more likely to have iodized salt than those who had not health information (AOR=8.96, 95\% I; 4.68-17.16) $(\mathrm{p}=0.03)$. Those who had good knowledge about iodized salt were 9.2 times more likely to have iodized salt than those who had poor knowledge $(\mathrm{AOR}=9.23,95 \% \mathrm{CI} ; 3.34-25.5)(\mathrm{p}=0.01)$. Those who used packed salt were 4 times more likely to have adequately iodized salt than those who used non packed salt (AOR=3.99, 95\% CI; 1.48-10.73) ( $\mathrm{p}=0.006$ ). Study participants who purchased salt from super market were less likely to have iodized salt than those who purchase from open market (AOR=0.026, 95\% CI; 0.004-0.197) $(\mathrm{p}=0.001)$ (Table 4).

\subsection{Discussion and Analysis}

Availability and consumption of adequately iodized salt must be granted for sustainable elimination of IDD. According to WHO and International Council for Control of Iodine Deficiency Disorders (ICCIDD) standard, IDD will be possible if more than $90 \%$ of the households consume adequately iodized salt. Ethiopia, in its national guideline for control and prevention of micronutrient deficiencies, has set a goal to virtually eliminate IDD by the year 2005 through universal salt iodization (USI) and an objective to increase access to iodized salt among households up to 80\% [9-10]. But according to the EDHS 2011 report, the national coverage of USI was only $15.4 \%$ [5].

In this study, $7.5 \%$ (95\% CI; 5.6-9.5) of the households had adequately iodized salt at household level. This is lower than a study conducted in Gondor town (28.9\%) Benishangul-Gumuz (39.7\%), Oromiya (19.4\%), Tigray region (22.3\%), Addis Ababa city administration (29.6\%) and Ethiopian Somalia Region (19.2\%) [5], [8]. This difference might be due to a sample size, a poor knowledge of a community about iodine fortified salt and a poor implementation of a strategies at the production site and distribution of iodized salt at the retailer level to enhance universal salt iodization program, a poor regular follow up and monitoring regarding of iodized salt. Whereas, this finding is higher than iodized salt coverage of EDHS 2011 report in Dire Dawa City Administration (5.7\%) [5]. this difference might be due to variations in sample size and study settings. EDHS was conducted both in urban and rural areas but the present study was conducted entirely in urban setting. Urban dwellers used iodized salt more as compared to rural dwellers as evidenced from EDHS 2011[5].

In this study, health information regardin iodized salt was significantly associated with availability of adequate iodized salt (AOR=8.96, 95\% I; 4.68-17.16). Majority, (97.6\%) study participants did not receive any information or health education about iodized salt and IDD from health workers or others sources. A study conducted in Laelay Maychew District, Northern Ethiopia, showed that $60.8 \%$ of the respondents obtained information from health care workers [11]. This might be due to poor initiation effort made by health workers and other collaborators in the dissemination of pertinent information and create awareness about the importance of consuming iodized salt in the study area.

Knowledge of study participants about iodized salt was significantly associated with the outcome variable in this study (AOR=9.23, 95\% CI; 3.34-25.5). In this study, 598 (86.16\%) study participants had poor knowledge about iodized salt and its consequences. This is consistent with a report in Gondor town (74.8\%) [8].

A report in Bia District, Ghana indicated that having good knowledge about iodized salt was positively associated with utilization of adequately iodized salt in the household [12]. This might be due to increased knowledge regarding the importance of using iodized salt and the effects of its deficiency in the diet of an individual; there has also been an increase in the consumption rate of iodized salt. However, a study from Hawassa town, Sothern Ethiopia, revealed that having knowledge about iodized salt was not significantly associated with the use of adequately iodized salt [13]. This variation might be due to differences in study population and instruments used to measure knowledge.

In this study, using packed salt at the household level was significantly associated with availability of adequate iodized salt at households (AOR=3.99, 95\% CI; 1.48-10.73). In the present study, 505 (72.8\%) of the respondents were using none packed and out of which $458(90.7 \%)$ of the samples had no adequate concentration of iodine in salt $(<15 \mathrm{ppm})$. A report in Gonder, Northwest Ethiopia showed that $669(83 \%)$ households were used non packed salt; of these 544(81.5\%) were inadequately iodized. The remaining 141 (17\%) households used packed salt, and out of these, 109(77.3\%) were adequately 
iodized salt [8]. A study conducted in North Parganas District of West Bengal, India indicated that (83.3\%) households were purchasing non -packed salt and consume inadequately iodized salt compared to others (22.4\%) who always purchased salt in the sealed packet (PR: 2.9, 95\% CI 1.8-4.8) [14]. This might be due the nature of transportation system, packing material, conditions, amount of packaged iodine fortified salt storage, and keeping it in a suitable environmental condition.

\section{CONCLUSION}

The availability of adequate iodized salt at household level was very low as compared to the WHO recommendation to prevent IDD. Based on the findings of this study, we can conclude that availability of adequately iodized salt at household level was very low in Dire Dawa town. Health information about iodized salt, knowledge of participants and type of salt used and place of purchasing salt were identified as factors as sociated with availability of adequately iodized salt at household level. Nutrition educat ion program regarding about iodized salt and the importance of iodized salt needs to be implemented to promote the awareness of the community. Hence, households should be sensitized regarding the importance of iodized salt and its proper handling at the household level.

\section{ACKNOWLEDGMENTS}

The authors would like to thank Haramaya University, College of Health and Medical Sciences, for supporting the primary author. Moreover, we would like to extend our heartfelt gratitude to the Ethiopia Food, Medicine and Health Care Administration and Control Authority, Eastern Branch for permitting us to use their laboratory and providing technical supports during laboratory works.

\section{REFERENCES}

[1] M. Venkatesh and T. John, "Salt Iodization for the Elimination of Iodine Deficiency,"International Council for Control of Iodine Deficiency Disorders, Amsterdam, The Netherlands, 1st edition, 1995.

[2] P.Jooste and M. A. V.Assey, "ICCIDD Iodine Network, Cape Town, South Africa; Zurich, Switzerland; and Dar Es Salaam, Tanzania,"IDD Newsletter, 2013.

[3] Andersson M. and Zimmerman M. B., "Global iodine nutrition: a remarkable leap forward in the past decade,"IDD Newsletter, vol/issue: 40(1), pp. 1-5, 2012.

[4] Federal Democratic Republic of Ethiopia, Regulation No.204/2011, "Salt Iodization Council of Ministers Regulation. Federal NegaritGazeta FDRE,” vol/issue: 17(28), pp. 5785-86, 2011.

[5] Central Statistics Authority of Ethiopia/ICF, "International, Ethiopia Demographic and Health survey, Addis Ababa,"2011.

[6] International Council for Control of Iodine Deficiency Disorders, Elimination of iodine deficiency through salt iodization in Ethiopia, "Summary Report on Situation Analysis of Iodine Deficiency \& Disorder \& Universal Salt Iodization in Ethiopia," ICCIDD, 2012.

[7] FDRE Population census Central statics agency, "The 2007 population and housing census of Ethiopia results for Dire Dawa city administration statstic report. Dire Dawa Profile, Dire Dawa Demographic \& Health survey, Dire Dawa," 2010.

[8] H. G.Gebremariy am, et al., "Availability of Adequately Iodized Salt at Household Level and Associated Factors in Gondar Town, North west Ethiopia,” 2013.

[9] UNICEF, ICCID, PAMM, and WHO, "Monitoring Universal salt Iodization Program, PAMM/ICCIDD, Ottawa, Canada," 1995.

[10] FMOH, "National Guideline for Control and Prevention of Micronutrient Deficiencies," Edited by F. H. Department, Federal Ministry of Health, Addis Ababa, Ethiopia, 2010.

[11] Gidey B., et al., "Availability of Adequate Iodized Salt at Household Level and Associated Factors in Rural Communitiesof LaelayMaychew District, Northern Ethiopia: A Cross Sectional Study," J Nutr Health Sci,vol/issue: 1(4), pp. 403, 2015. Doi: 10.15744/2393-9060.1.403.

[12] C. Buxton and B.Baguune, "Knowledge and practices of people in Bia District, Ghana, with regard to iodine deficiency disorders and intake of iodized salt," 2012.

[13] M.Girma, et al., "Iodine deficiency in primary school children and knowledge of iodine deficiency and iodized salt among caretakers in Hawassa Town: Southern Ethiopia," 2012. 
[14] T. K.Sen, et al., "Limited Access to Iodized Salt among the Poor and Disadvantaged in North ParganasDistrict of West Bengal, India," 2010. 